\title{
Transformative Peacebuilding Efforts in Northern Uganda: The Development of St. Monica's School of Basic Learning for Women
}

\author{
Adam Stroud, Julianna Lopez Kershen, Kate Raymond, Lindsay Williams, Sara Ann Beach \\ The University of Oklahoma, USA
}

\begin{abstract}
This paper describes a snapshot of the recursive stages and ongoing, evolutionary development of St. Monica's School of Basic Learning for Women in Gulu, Uganda. The purpose of this paper is to describe the collaborative efforts between Sister Rosemary Nyirumbe and the faculty at St. Monica's School of Basic Learning for Women along with faculty and students at the university. This description highlights the theories underlying the servicelearning partnership, including postcolonial theory and education as a human right, while also providing a review of literature explicating conflict and peacebuilding efforts in northern Uganda, and the indigenous genesis of a new school for adult women. This paper also provides a brief narrative of the university team's initial experiences as partners engaging in cross-cultural, co-construction of school programming, professional development, and interdisciplinary curricular materials. Finally, this description closes with implications for future research.
\end{abstract}

\section{Introduction}

The purpose of this paper is to describe the collaborative efforts between St. Monica's School of Basic Learning for Women in Gulu, Uganda and the College of Education at a Midwestern university. Postcolonial theory underlies these efforts and provides a theoretical guide for the project. This paper aims to describe the collaborative development of St. Monica's School of Basic Learning for Women by first providing the contexts of recent armed conflicts and educational opportunities in northern Uganda. Next, we present a narrative portrait focused on the school's genesis, and the university team's first onsite constructivist efforts in Gulu, Uganda. This paper aims to explore how service-learning partnerships develop, the enactment of reflective practice, and the potential for educational opportunities for women to contribute to transformative peacebuilding efforts in the northern Uganda area.

In 1981 Yoweri Museveni and the National Resistance Movement/Army successfully initiated a guerrilla war that allowed Museveni to replace Milton Obote's second government [1]. Within two years of Museveni's takeover, there were 27 different rebel groups resisting the new government [2]. Of these, most notable is the Lord's Resistance Movement/Army (LRA), whose actions especially affected the Gulu, Kitgum, and Pader districts in northern Uganda [1]. By the end of 2003, multiple atrocities had been committed by the LRA against the populace: mutilation and summary execution of noncombatants and abduction of children and adults for use as soldiers, sex slaves, and porters [3]. The LRA used fear to recruit and coerce participants, and as a primary attack strategy and "force multiplier" to increase the size of their military presence in the area [4]. Conflicts between national government forces and the LRA caused upheaval in the lives of many northern Ugandans in the Acoli region, as women, men, and children suffered from socioeconomic and security vulnerabilities. These vulnerabilities manifested as high rates of illiteracy due to interrupted schooling, malnutrition from food shortage and lack of access to safe water, and inadequate and limited access to healthcare, resulting in widespread disease, including HIV infection [5].

St. Monica's School of Basic Learning for Women is but one evolving response to the atrocities that have impacted the Gulu area of northern Uganda. Throughout the area individuals and communities continue to work together to achieve a vision of hope through the establishment of educational, healthcare, and citizenship opportunities for people affected by conflict, especially marginalized women and children. Inspired by Freire's words, "without a vision for tomorrow, hope is impossible," [6] our team began a service-learning journey with Sister Rosemary Nyirumbe and the Gulu community. Although there is an established hope at St. Monica's school, the vision for women's education as transformative relies on educators' continued responsiveness to the specific needs of students. Such a hope is dependent on the voices of all individuals involved, most importantly the Ugandan students and educators. As "outside" partners in this co-constructive endeavor, our university team strives to acknowledge the legacy of colonialism while working to listen to and amplify the voices of our Uganda partners. In this way, as the collaborative efforts move forward to develop educational programs for this group of women, we remain vigilant as to how our cultural identities and experiences influence decision-making. Selfreflection, individually and collectively, requires us to 
consider the spaces we occupy and words we use. Effective education remains in jeopardy regarding the culture at large or with the constituencies who are more dedicated to maintaining the status quo than working to foster flexibility [7]. Uganda's postcolonial attempts at adopting social transformative goals and the tensions that developed into conflict [3], we are watchful as to how our work may contribute to misunderstandings within the cultures and communities of northern Uganda.

\section{Postcolonial Theory}

Education is often understood as a path to economic prosperity. Although we recognize the power of education to act as currency in the workplace, education is also a road to emancipation, empowerment, and hope. At the invitation of our Ugandan partners, and stirred by our beliefs in the potential that an international, interdisciplinary university-community service-learning partnership would improve our own lives and the lives of others, we began this endeavor. Although we have yet to formally research the evolving partnership, the collective enterprise continues to gain support in the Gulu community. Working on an international development project specific to sub-Saharan Africa may have the purpose of improving the living conditions of others, however, it also challenges its architects to act within a framework that is noncolonial, collaborative, and inclusive [8]. Throughout this project, it has been critical that our efforts do not imitate previous ways in which "Western powers have adopted a 'therapy' approach in which they keep 'helping' others until they get them assimilated and changed to the way they want them to be" [8]. Efforts must be made to recognize "a multitude of voices of the historically marginalized and to work toward a theory of translation, a hermeneutics that makes it possible for the needs, aspirations and practices of a given culture to be understood by another" [9]. In order for an individual to step outside of their current social roles individuals need hope, courage, and motivation to find ways to break away from hopelessness [10]. In working with the individuals at St. Monica's School of Basic Learning for women, we have all felt, seen, and been influenced by the constant hope, courage, and motivation that surrounds that space. For the purposes of this article, a review of the professional literature that has informed our efforts focus on Uganda as a post conflict setting, for the purposes of this article, a review of the professional literature regarding the contexts of Uganda as a post conflict setting and the influences of education on girls, women, families, communities and the country is discussed.

\section{Literature Review}

\subsection{Gender and Education in Uganda}

Women play multiple roles within the family and community in northern Uganda, serving as primary caregivers for children and family while also directing domestic work and seeking income through work outside the home. The typical day for a Ugandan woman, which starts before sunrise and ends well after sundown, can include: sweeping the compound, cleaning the house, chopping firewood, cooking breakfast, getting children ready for school, working in the garden, walking between $5-10 \mathrm{~km}$ to collect water, cooking lunch as children return from school, collect more water, pounding cassava (described as a very strenuous task), cooking supper for the family, and sponge-bathing young children [11]. Gender roles and responsibilities for girls dictate the availability of time, leaving them with little or no time for school. Despite the many obstacles women and girls face, Ugandan women who hold such crucial intrinsic factors such as self-determination, motivation, and self-belief, are able to maintain a commitment to education despite setbacks and challenges that occur along the way [12].

However, even with extra time and determination to attend school, many women are still unable to make the decision to attend class. This indecision has been found to be connected to the patriarchal structures within communities in northern Uganda that make women's school attendance largely dependent on whether they have the support of their husbands [11]. Educational programs must account for the realities of women and consider the routines of others before making decisions to create alternatives that could disrupt established roles in the family and community. Emphasis should be placed on the importance for developers and planners to pay more attention to women's concrete realities and discover their real aspirations as opposed to goals assumed by the reformers [13]. Such a focus places the indigenous knowledge of women as the basis of policy and practice. Set within the contexts of St. Monica's School of Basic Learning for Women, we still must keep the realities of the students at the forefront of decisions regarding school policy. This view also extends to the pedagogy of the school. The school is then placed within an ongoing evolution to function as a place that supports the desires of those who attend. This ebb and flows between teachers, learners, and members of the community sets within real settings and local contexts [14]. When the realities of women are given top priority, education for women benefits not just an individual, but also benefits her family, community and country. 


\subsection{Influences on Children and Family}

Many of the students at St. Monica's School of Basic Learning for Women are mothers and caregivers. There is wide research indicating that women's access to educational attainment [15], and maternal literacy [16] positively affect children's learning and health outcomes. Findings from research indicate women retain into adulthood literacy skills taught in school, women's literacy predicts their ability to make informed decisions about nutrition and health for themselves and their families, and mothers with higher literacy skills are more likely to tutor their children and support their schooling [16]. For example, when parents are educated on issues such as spending dedicated time with children and taking an active interest in school related activities, the benefits are shared between parents, the children, and the wider society [17]. Although, it is important to consider differences across family structure and parental dynamics in Ugandan homes, it is especially important in Northern Uganda, where the lasting effects of conflict can be seen in the disruption of traditional family structures. Conflict has resulted in women serving as caregivers for children within their extended family, as well as community reintegration of women who, as child abductees by the LRA, have suffered interrupted schooling and, in some cases, given birth to children outside the bounds of cultural traditions of marriage. Conflict in Northern Uganda then has played an especially deleterious role in women's and girls' access to formal schooling, and thus has also negatively impacted children's schooling and health. For example, in the instances where the father could not, or chose not to support the family, the mother's involvement in education became crucial [12]. In addition, research has shown that in Ugandan homes the levels of education for the mother and father to help their children achieve higher in school are not the same [15]. Furthermore, in a study of 5,148 sixth grade students enrolled in 163 randomly selected primary schools in Uganda, it was found that a mother needed a secondary education to predict that her child would achieve higher in reading, and a post-secondary education for higher achievement in numeracy [15]. Expanding beyond literacy and numeracy education, especially of mothers, is also a pivotal factor in improving children's nutrition, disease prevention and health in post conflict countries. Research indicates that improving educational opportunities and access for individuals within the larger family unit (i.e., beyond the mother-child pair), and even within the community, can positively affect children's health [18]. This research may hold important lessons for increasing access to formal education in northern Uganda, where women and girls often care for children outside the birth mother-child relationship.

\subsection{Influences on the Community and Country}

In sub-Saharan Africa, the gender parity index, which is calculated by taking the female literacy rate and dividing that by the male literacy rate, indicates that women aged 15 years and older are $24 \%$ less likely to be literate when compared to men of the same age [19]. Providing women with educational opportunities not only closes the gender parity index, but can result in economic increases as well. Because the average girl with a secondary education has an $18 \%$ return in future wages, when compared to boys having a $14 \%$ return, the World Bank found that a $1 \%$ increase in the proportion of women with secondary education can increase a country's annual per capita income growth rate by .3\% [20]. Conversely, there is significant research showing the negative effects of women without educational opportunities. Research found that it is evident that the effect of non-literacy is detrimental to women in terms of their limited ability to obtain and understand important information, lower personal income, and lower selfesteem which can lead to seclusion [21]. Women who do have access to programs to help build literacy skills provide support for individuals sharing similar challenges. Research efforts have sought to examine how the roles of women in the community change as they seek to build their literacy skills by enrolling in literacy programs. It is reported that literacy classes provide important spaces for women to reconstruct their identity and belonging as emerging members of their families and give them the opportunity to live in an imagined community where they had a sense of belonging and being valued [11].

\section{The Development of St. Monica's School of Basic Learning for Women}

In 1989, the Ugandan government's Education Policy Review Commission recommended instituting universal primary education [22]. In 1997, after the first direct presidential elections in Uganda, the newly elected Yoweri Museveni announced the elimination of school fees for primary education [23]. No age limits were included in the policies and thus, theoretically women who had their educations interrupted by the war were able to return to school. However, in practice, both hygiene issues and family care issues make it infeasible for most adult women to return to traditional primary school. The schools are often not equipped to deal with feminine hygiene issues. In addition, many adult women are responsible for the care of young children during the day or must work to provide for their families during the day, thus making attendance at a traditional school challenging if not impossible. A third obstacle for women who were abducted by the LRA is the fear and distrust with 
which they are viewed by local communities because of their past affiliation with the rebels [24].

By 2002, Sister Rosemary Nyirumbe had taken charge of a little utilized vocational school for girls, called St. Monica's Tailoring School, in Gulu, Uganda. Gulu is a major commerce center in Northern Uganda, and also a regional nexus wherein many LRA actions occurred. Sister Rosemary began recruiting young women, many of whom had experienced trauma due to the LRA conflict. She encouraged these women to attend the school so as to learn practical skills such as sewing, pattern making, and cooking. The goal was to provide women with marketable skills that they could use to support themselves and their children. Over time the school and its programming expanded to include courses in culinary arts and hairdressing. As women graduated from these programs with both practical skills and selfconfidence, many began to express the desire to have learning opportunities similar to more traditional academic education in addition to their practical learning. These women shared their frustrations focused on how their limited English proficiency, and for some illiteracy, limited their ability to interact within the larger Gulu community in meaningful ways. For instance, some women shared that they were unable to read signs in town, discern healthcare and childcare options, or understand when financial transactions were unfair or unjust. Many suspected they may be taken advantage of within their place of work or in the market, but felt helpless to intercede because of limited literacy and numeracy skills, often in both Acoli, the local most prominent language in the Gulu area and in English, the lingua franca of commerce and education across Uganda.

However, it was not until one of the women Sister Rosemary worked with was misquoted and misrepresented in an English language newspaper article that Sister Rosemary determined to develop a pathway for the provision of more formal education opportunities. Within the article, Sister Rosemary's student sought to communicate her fear that the LRA would attempt to recapture her. However, her limited proficiency in English caused misunderstanding, and the writer of the article instead conveyed that this woman, one of many former wives of LRA leader Joseph Kony, had thoughts of returning to the LRA. This gross misunderstanding inspired Sister Rosemary to begin an endeavor to provide interested women classes in basic literacy and mathematics skills. Sister Rosemary felt that every woman deserved the opportunity to express herself and to be understood. This story served, and continues to serve, as a motivating catalyst for the development of the School of Basic Learning for Women.

By 2015, Sister Rosemary had established a nonprofit organization, the Sewing Hope Foundation, with the help of Reggie Whitten, an Oklahoma attorney. Mr. Whitten travelled to Gulu many times and developed a friendship with and deep respect for Sister Rosemary and her work. He is determined to assist Sr. Rosemary's efforts to improve the lives of women in Uganda. With his assistance, Sr. Rosemary reached out to the university to determine if it could help to facilitate the development of a primary school for adult women in Gulu. Shortly after, a small group of faculty, including an Associate Dean of the College of Education at the university, visited St. Monica's and the Gulu community. Upon their return, the Associate Dean invited faculty within the college to consider leading this effort. Because of her experience in international literacy efforts, (author 5) met with the initial team to investigate the feasibility of establishing an accelerated primary school to meet the needs of the women in Gulu. (Author 5) has extensive experience working in professional development with teachers in developing nations. She began to work with Sr. Rosemary and the leadership in the College of Education to outline a plan to facilitate the development of the school, including a limited amount of funding for travel, resources, and additional personnel that could provide content expertise. During the 2015-2016 academic year, (author 5) recruited the remainder of the faculty/graduate team to join as the leadership team. (Author 2), a postdoctoral fellow, was recruited to help develop both the English language and literacy curriculums. Doctoral students (author 3), (author 4), and (author 1), all studying in the College of Education, were also recruited to develop the mathematics, social studies, and science curriculums, respectively.

\subsection{Envisioning Our Work}

We began our work prioritizing two goals: to develop the structure of the curriculum, including specific units of instruction, and to develop a sense of partnership and community with our counterparts in Gulu, including the newly recruited teachers. We felt that developing an overarching structure of the school curriculum would help establish goals for instruction and give our partners in Gulu a starting point as they began to plan for their classes. Equally important, however, was the establishment of a working relationship in which the university and Gulu partners were seen as complementary equals; we could offer pedagogical expertise while our counterparts had expertise in the local culture and schooling traditions. Post-colonialism guided our efforts; we did not seek to enter the St. Monica's community as experts demanding compliance, but rather equal participants seeking to learn about the community its ways of knowing and learning [25]. We were keenly aware of our limited knowledge of the history and cultures of Uganda and sought to learn more about the culture through our partners. We sought to create a school 
which would affirm and empower the students and teachers with whom we would be working.

\subsection{Early Lessons in Developing Partnerships}

Of the many lessons we learned during the first trip to Gulu, one of the most dominant and difficult to describe in its entirety, was the depths to which colonialism within the education system, and especially within the minds of adult learners and teachers, still prevailed in Uganda. We first met with the teachers recruited to teach within the new school during a weeklong visit in March of 2016. In order to establish our roles as learners, as well as teachers, within the first meeting we asked for a lesson in Acoli from our new colleagues. In this teaching and learning experience we learned basic greetings and pleasantries, and the Ugandan teachers seemed confident and comfortable in their roles while teaching us the lesson. Learning how to properly greet others proved to be challenging for some of our team members, as the proper way to address another person within the local community depended not simply on the person, but also on the particular context within which they are being addressed. For example, our new colleagues explained to us that greetings for elders were different than the greetings for younger people. However, a student, regardless of age, addressing a teacher would always use the greeting for an elder, regardless of the age of the teacher. Similarly, a teacher addressing a student would always address them as they would a younger person, regardless of their actual ages. Our team reflected on the experience of learning formal greetings as one example of the legacy of hierarchical status in coloniality continues to shape day to day interactions. Within this initial meeting, we also invited our Ugandan teacherpartners to simply address us by our first names, expecting that we would interact with them in the same ways. In this way, collegial behaviors that felt casual and comfortable to us, we realized, may have felt odd or uncomfortable to our Ugandan colleagues. Over time this first name interaction was generally accepted, however we noted that our partners in Gulu had difficulty addressing (author 5), our team leader, by her first name. At that first meeting, after our Acoli lesson, we invited our partners to share their vision, ideas, and goals for the developing school. Despite their previous comfort with teaching us to greet one another in Acoli, this question unexpectedly changed the dynamic between ourselves and our partners. At this question, our Ugandan partners quickly shifted to a hierarchal pattern of deference: within both the discourse exchanges between one another, and the discourse interactions between our team and the Ugandan teachers. The conversation between the teachers changed to one in which we observed the female teachers looking to their male colleagues before speaking. The male teachers began to defer comments and ideas to the sole nun who was participating in our group. As our team began to interject and present ideas into the conversation, our partners also began to defer their comments to ours, in a way that we understood to be affirming that they would implement our ideas with little discussion or questioning. Our team met together after this meeting and reflected on our personal and, collective discomfort at how readily our Ugandan colleagues appeared to "agree" with our ideas. We recognized that the deference displayed to us, while it could be understood as communicating respect, also served as a harbinger for the true, mutually-respectful relationship building that was to come. At the end of the meeting, we asked our Gulu partners to prepare short mini-lessons for our next meeting so that we could learn what teaching and learning was like in Gulu.

When presenting these mini-lessons at our next meeting, our partners again shifted easily into their role as teachers. When we began to take notes during the first mini lesson, we were quickly corrected and told that note-taking would come after the discussion. We were also instructed on the customary ways to clap for ourselves and others when appropriate. Yet, when the mini- lessons were over and we began to discuss plans for the remainder of our trip and for the school, our partners returned to deferring to us or to the males in the group. We began to be concerned that we were being told what our partners believed we wanted to hear, rather than their honest opinions. Awareness shifted to the recognition and experience concerning the after effects of colonialism within learning and teaching interactions, realizations about implicit meanings within shifts in conversational patterns and tone, and the need to work explicitly to establish mutually-respectful professional relationships amongst our team and our Ugandan colleagues during this development process.

In our next meeting, however, we seemed to reach a milestone. The purpose of this meeting was to share the assessments we had created for the incoming students with our partners in Gulu, so that we, as a team, could begin the assessment process the next day. We began by sharing the assessment of English language ability. Based on sound learning and assessment principles, the assessment asked students to examine a culturally appropriate picture and describe what they saw in English. As we shared our thinking, our partners became even more quiet than usual. After much questioning, one of the teachers volunteered that the students we were to assess would be uncomfortable with this activity and suggested that the assessment be formatted as an interview where the students were able to talk about themselves and their families instead. We spent the rest of the morning rewriting and revising a new assessment for English language that the teachers felt would be more appropriate for the students. We felt this represented 
a milestone in our relationship because we were able to respond positively to the input given to us.

As we moved on to discuss the assessment in literacy and mathematics, the teachers seemed to be more comfortable making suggestions and changes. The day ended with providing each teacher a fully developed mathematics unit as an example of the type of resource we could write and provide for them. Two of the four teachers present provided written feedback on the unit and its structure. Finally, the team worked together to draft a mission statement for the school. After several versions were written and revised based on input from every member of the team, we agreed on the following mission statement: The school participates in the empowerment of women through the provision of quality basic education and other life and practical skills which support and enhance their efforts in parenting, contributing to society, and improving their quality of life and the lives of their children. Maintaining a relationship strongly grounded in the idea of developing relationships in a postcolonial era that does not manifest into a onedimensional view that reflect world hierarchies and divisions [8] is important as we continue to move forward in our work. Because of the limited time we have working with our partners on the ground in Gulu, like the mission statement, developing a curriculum responsive to the needs of the students has required many revisions and restarts, as our partners begin to share more of their thinking about the needs of their students.

\subsection{Curriculum and Professional Development}

Since we were working from a post-colonial mindset, it was important that we not impose a US curriculum on the school. We knew that many women who would attend primarily wanted to learn English language skills to be able to speak, read and write. Additionally, the women wanted to use mathematics more effectively to be able to better their own circumstances and be able to speak for themselves. We also anticipated that some of the women would want to continue their education. We knew we had to prepare those interested women for the high stakes test they would have to pass to enter secondary education.

Hence, we began to look for a copy of the Ugandan primary curriculum in the subjects that would be tested: English, mathematics, social studies and science. Both groups of women would come to the school with varying levels of English language proficiency, literacy skills, and mathematics knowledge, so the first step was to create screening assessments that would be culturally relevant while enabling the teaching staff to know what skills and abilities the women were bringing to school. As the Ugandan primary grades curriculum was created for children to progress through over the course of seven years, we knew that we would need to condense the content into three to four years. Also, the curriculum needed to be organized in such a way that it honored the knowledge that the adult students would bring about their communities and the world around them while supporting their development of English language and literacy skills. It was also important that lessons and activities be relevant to the lives of the women and that teaching practices be grounded in principles of active, participatory, emancipatory learning. We decided that a curriculum organization to support these key principles would be one of cross disciplinary units that integrated familiar concepts in social studies and science along with English language and literacy lessons and mathematics concepts as appropriate. Curricular concepts in science and social studies were reviewed and combined into seven overarching themes. The concepts making up the themes were identified and sequenced from simple to complex and ordered into specific units of instruction. The concepts that were more simple and familiar to adults were integrated into the English oral language units that would make up the first two years of schooling. The focus of those units would not be to teach new concepts about the world as a teacher might do in the early primary grades but to use the women's knowledge for how the world worked to teach English vocabulary and sentence structures as well as support their reading and writing ability.

Our perspective shared foundational beliefs with the researchers who define literacy, and being literate, as differing from context to context [26]. Because of this guiding framework, and coupled with postcolonial theory, we have collaborated with our Ugandan partners to develop literacy and numeracy lessons and materials that are pertinent within the everyday context for women in the Gulu area. These curricular materials have been revised, and continue to be revised, under the guidance of our Uganda colleagues. We recognize that increasing women's access to literacy and numeracy means more than simply creating school sites and coursework. For us, access includes supporting women to develop positive learning identities and self-efficacy as learners, through the inclusion of an asset-based approach that meets learners where they are, actively engaging our students as partners in the education process, and communicating positive progress to learners so that they are motivated to attend classes and stay in the programming. In this way, we are cognizant of the importance of teaching the meta-narratives of schooling to our women students, such as attentional space in the classroom, how to use materials and tools to learn academic content, ways of tracking one's learning through note-taking, drawing, and practice, and materials and conversational skills for at home 
practice of reading, writing, and mathematics practice with children in the home.

Additionally, the design and redesign of materials utilizes an interdisciplinary approach, with clear modeling for teachers and learners around the use of academic vocabulary and disciplinary language, as well as text structures and linguistic features that serve to promote deeper inquire into content learning. This approach is also spiraling, thus designed to iteratively return to key content concepts within the Ugandan primary curriculums of English, mathematics, science, and social studies, and academic reading and writing processes over the course of multiple units of study.

Finally, the materials under development include explicit parent-child activities, as well as inclusion of topics of interest generated by the adult women enrolled in the school such as reading and responding to citizenship issues, current events, workplace documents, and public service documents related to accessing healthcare. For the mathematics curriculum, it became evident that the women relied on ways of knowing mathematics that had been culturally developed and learned. For example, while most of the women cooked regularly, a system of color coded measuring scoops reframed measurements in cooking. The system allowed recipes to determine amounts needed by the color of the scoops being used. For example, a recipe might call for two red scoops or one blue scoop of an ingredient. Thus, as the women engaged in their daily cooking, they developed reasoning around ratios and proportions. For example, they could explain how many red cups was equivalent to a blue cup. However, this representation of measurement did not help to develop the women's sense of fractions, as the U.S. Customary units of half and quarter measurements might.

Additionally, many of the women performed basic calculations in ways not widely known in the US. For example, many women used a system of repeated doubles to multiply numbers. For example, to multiply five and seven, they would first double five to find the product of five and two, then double their result again to find the product of five and four. They would then reason that seven was equivalent to a single five, plus double five, plus quadruple five, and add their results. Because of these insights into the mathematical understandings of the women, the mathematics curriculum strove to provide women with opportunities to first express their own understandings of mathematical concepts and then use their own ways of knowing to extend their understanding.

\section{Implications for future research}

Future research may use a two-prong case study design [27]: one line of research investigating the experiences of the graduate and faculty group responsible for school and curricular development and a second line of research examining the undergraduate students involved in the service learning and travel experiences in Gulu. These investigations may be descriptive and phenomenological, aiming to document participants' experiences so as to better understand postcolonial service work in action, and thus informing the ongoing work in Gulu and, more generally, university service-learning projects partnering between former colonizers and postcolonial states. Such research will require at least three forms of data collection: detailed ethnographic work, including closely developed field notes through participant observation in context [28], and semistructured interviews [29].

\subsection{Theoretical frames and methodologies}

Additionally, the first line of study will require the use of self-study methods focused primarily on selfgenerated and self-reported narratives/storytelling, critical incidents, and responses to shared reading [30]. Utilizing narratives and the identification of critical incidents provides the graduate/faculty development team the venue for analyzing our epistemologies and (pre)dispositions. Self-study is borne out of the desire to better understand, and thus improve one's practice [30]. Such self-study is both autobiographical and collective [31], and in this way, containing many voices and many areas of interest (i.e., it is multi-vocal and multi-focal). Autobiographical study in education assists educators in considering how past experiences inform current practice, as well as waking us up to mindful engagement with learners, formally and informally [31]. This work would require the explicit acknowledgement of an ethnographic stance, recognizing the multiplicity within each of the participants, including examinations of bias and ethnocentrism, an examination especially salient because of international context of this work. With regards to possible theoretical frames for data analysis, such research may draw from a number of methods and theories. We offer the following as possible best fits moving forward, as complement to the case method research design. Narrative analysis methods will be well-suited to the analysis of critical incident stories and the subsequent questions arising from descriptions of problems of practice that we wrestle to understand [32]. Narrative inquiry methodology $[34,35]$; seeks to utilize stories as means of understanding another's experience and meaning making. This methodology is both a way to study experience and a way to understand it, thus it is a method used in research design, data analysis, and writing about data. Within this methodological construct, the role of the researcher is as coconstructor of knowledge and story. As such, it is 
paramount that the researcher engages in reflexive writing and conversation with the participants and the data set. In this way, the researcher recognizes her/his role in the construction and selection of meaning, and the limitations therein [34]. Because this study seeks to understand the effects and quality of participation in the service-learning experience, the reflective stance privileged by narrative inquiry methods is appropriate.

\section{References}

[1] Finnstrom, Sverker. "Wars of the Past and War in the Present: The Lord's Resistance Movement/Army in Uganda." Africa: Journal of the International Africa Institute 76, no. 2 (May 2006): 200-20. https://doi.org/10.3366/afr.2006.76.2.200.

[2] Bond, G. C., and J. Vincent. "The moving frontier of AIDS in Uganda: contexts, texts and concepts. ." In Contested Terrains and Constructed Categories: Contemporary Africa in Focus. Boulder, Colorado: Westview Press, 2002.

[3] Acker, Frank Van. "Uganda and the Lord's Resistance Army: The New Order No One Ordered." African Affairs, 103, no. 412 (2004): 335-357

[4] Vinci, Anthony. "The Strategic Use of Fear by the Lord's Resistance Army." Small Wars \& Insurgencies 16, no.3 (2005).

[5] Atekyereza, Peter Rwagara. "Deprivation, HIV, and AIDS in northern Uganda." African Sociological Review 18, no. 11 (2014): 91-111. http://www.jstor.org/stable/afrisocirevi.18.1.91.

[6] Freire, Paulo, Donaldo P. Macedo, Alexandre K. Oliveira, Martin Carnoy, Ladislau Dowbor, Ana Maria Araújo Freire, and Paulo Freire. Pedagogy of the heart. London: Bloomsbury Academic, 2016.

[7] Bruner, Jerome. The Culture of Education. Cambridge, MA: Harvard University Press.

[8] Shizha, Edward, Makuvaza, Ngoni. "Re-thinking Education in Postcolonial Sub-Saharan Africa PostMillennium Development Goals." in Re-thinking Postcolonial Education in Sub-Saharan Africa in the 21st Century. Rotterdam, The Netherlands: Sense Publishers, 2017.

[9] Tikly, Leon. "Education and the new imperialism." Comparative Education 40, no. 2 (2004): 173-98. doi:10.1080/0305006042000231347.

[10] Greene, Maxine. Releasing the Imagination: Essays on Education, the Arts, and Social Science. San Francisco, California: Jossey-Bass, 1995.

[11] Kendrick, Maureen E., Hissani, Hizzaya. "Letters, Imagined Communities, and Literate Identities: Perspectives from Rural Ugandan Women." Journal of Literacy Research 39, no. 2 (2007): 195-216.
[12] Warrington, Molly. "Challenging the Status Quo: The Enabling Role of Gender Sensitive Fathers, Inspirational Mothers and Surrogate Parents in Uganda." Educational Review, 65, no. 4 (2013): 402-415.

[13] Nzomo, Maria. "Women and Democratization Struggles in Africa: What Relevance to Postmodernist Discourse." Feminism, Postmodernism, Development. (1995), 131-41.

[14] Leach, Jenny, and Bob Moon. The power of pedagogy. Sage, 2008.

[15] Wamala, Robert, Omala Saint Kizito, and Evans Jjemba. "Academic Achievement of Ugandan Sixth Grade Students: Influence of Parents Education Levels." Contemporary Issues in Education Research (CIER) 6, no. 1 (2013): 133. doi:10.19030/cier.v6i1.7612.

[16] Levine, Robert A., Sarah Levine, Beatrice SchnellAnzolla, Meredith L. Rowe, and Emily Dexter. Literacy and Mothering: How Women's Schooling Changes the Lives of World's Children. Oxford, UK: Oxford University Press, 2012.

[17] Drajea, Alice, and Carmel O'Sullivan. "Influence of Parental Education and Family Income on Children's Education in Rural Uganda." Global Education Review 1, no.3 (2014):149-166.

[18] Moestue, H., and S. Huttly. "Adult education and child nutrition: the role of family and community." Journal of Epidemiology \& Community Health 62, no. 2 (2008): 15359. doi:10.1136/jech.2006.058578.

[19] United Nations Educational, Scientific and Cultural Organization. "Adult and Youth Literacy." UIS Fact Sheet, no. 32 (September 2015): 1-6.

[20] Wade, Sarah. "5 Reasons You Should Care About Girls' Education." United Nations Foundation 5 Reasons You Should Care About Girls Education Comments. January 13, 2014. Accessed September 08, 2017. http://unfoundationblog.org/5-reasons/.

[21] Akello, Judith Abal, Evelyn Lutwama-Rukundo, and Peace Musiimenta. "Functional Adult Literacy: An Alternative Gateway to Grassroots Women's Improved Income Generation in Lango Subregion, Northern Uganda." Adult Education Quarterly 67, no. 2 (2017): 79-96.

[22] Stasavage, David. "The role of democracy in Uganda's move to universal primary education." The Journal of Modern African Studies 43, no. 1 (2005): 53-73. doi:10.1017/s0022278x04000618.

[23] Grogan, Louise. "Universal Primary Education and School Entry in Uganda." Journal of African Economies 18, no. 2 (March 1, 2009): 183-211. https://doi.org/10.1093/jae/ejn015.

[24] Whitten, R., and N. Henderson. Sewing Hope. Oklahoma City, OK: Dust Jacket Press, 2013. 
[25] Werbner, Richard. "The Personal, the Political and the Moral." In Postcolonial Subjectivities in Africa, 1-22. London, UK: Zed Books Ltd., 2002.

[26] Street, Chris. "A Reluctant Writers Entry Into a Community of Writers." Journal of Adolescent \& Adult Literacy 48, no. 8 (2005): 636-41. doi:10.1598/jaal.48.8.1.

[27] Barone, Diane M. "Case Study Research." In Literacy Research Methodologies, 7-27. 2nd ed. New York, NY: The Guilford Press, 2011.

[28] Emerson, R. M., R. I. Fretz, and L. L. Shaw. Writing ethnographic fieldnotes. Chicago, IL: The University of Chicago Press, 1995.

[29] Seidman, Irving. Interviewing as qualitative research. New York, NY: Teachers College Press, 1998.

[30] Laboskey, Vicki Kubler. "The Methodology of SelfStudy and Its Theoretical Underpinnings." International Handbook of Self-Study of Teaching and Teacher Education Practices, 2004, 817-69. doi:10.1007/978-14020-6545-3_21.

[31] Coia, L., and M. Taylor. "Co/autoethnography: Exploring Our Teaching Selves Collaboratively." In Research Methods for the self-study of practice, 3-16. Dordrecht, Netherlands: Springer, 2009.

[32] Anderson, Gary L., Kathryn Herr, and Ann Sigrid Nihlen. Studying your own school: an educators guide to practitioner action research. Thousand Oaks: Corwin Press, 2007.

[33] Orland-Barak, Lily, and Hayuta Yinon. "Sometimes a novice and sometimes an expert: mentors' professional expertise as revealed through their stories of critical incidents." Oxford Review of Education 31, no. 4 (2005): 557-78. doi:10.1080/03054980500355468.

[34] Clandinin, D. Jean. Engaging in narrative inquiry. Walnut Creek, CA: Left Coast Press, 2013.

[35] Clandinin, D. Jean, and F. Michael Connelly. Narrative inquiry: experience and story in qualitative research. San Francisco: Jossey-Bass Publishers, 2000. 